\title{
Fibrin-glue assisted multilayered amniotic membrane transplantation in surgical management of pediatric corneal limbal dermoid: a novel approach
}

\author{
Amir Pirouzian • Hang Ly • Huck Holz • \\ Rattehalli S. Sudesh • Roy S. Chuck
}

Received: 3 April 2010 /Revised: 4 August 2010 / Accepted: 16 August 2010 /Published online: 7 September 2010

(C) The Author(s) 2010. This article is published with open access at Springerlink.com

\begin{abstract}
Purpose To report a new surgical technique for excising pediatric corneal limbal dermoid and the post-resection ocular surface reconstruction.

Methods We describe a method of deep lamellar excision followed by sutureless multilayered amniotic membrane transplantation in surgical management of corneal limbal dermoid.

Result This technique achieves a rapid corneal re-epithelization, reduces post-operative pain, and will diminish post-operative scarring. Preoperative corneal astigmatism will persist.

Conclusion This method offers an alternative surgical approach in comparison to simple excision in removal of simple pediatric corneal limbal dermoids.
\end{abstract}

Keywords Pediatric $\cdot$ Limbal dermoid .

Amniotic membrane · Fibrin glue

Amir Pirouzian as the principal author takes responsibility for the integrity of the data and the accuracy of the data analysis. No potential conflict of interest exists for authors.

Authors do not report any financial interest in any reported items.

A. Pirouzian $(\bowtie) \cdot$ H. Holz $\cdot$ R. S. Sudesh

Department Ophthalmology, Kaiser Permanente Medical Group,

710 Lawrence Expressway, \#490,

Santa Clara, CA 95051, USA

e-mail: amirpirouzian@msn.com

H. Ly

Kaiser Permanente Medical Group,

Milpitas, CA, USA

R. S. Chuck

Albert Einstein College of Medicine,

Bronx, NY, USA

\section{Introduction}

Epibulbar dermoids are choristomas of a single lesion or multiple lesions involving central or perilimbal cornea, conjunctiva and/or periocular tissues. They are typically slow-growing, minimally vascularized whitish lesions generally located in inferotemporal quadrant [1-4]. Anatomically they have been classified into three grades.[5] The first grade, the limbal or epibulbar dermoid, is a superficial tumor lesion less than $5 \mathrm{~mm}$ localized on the corneal limbus. The second grade is a large dermoid covering the majority of cornea and extending deep to Descemet's membrane without involving it. The third grade, the least common, is a large dermoid covering the whole cornea and extending deep, affecting all histological structures between the anterior surface of the eyeball and pigmented epithelium of the iris. Despite their benign nature, epibulbar dermoids may affect vision by gradually inducing corneal astigmatism resulting in anisometropic amblyopia [6]. Enlarging limbal dermoids may also cause disturbance to the ocular surface tear film, forming dellen that result in surface irritation and discomfort [6].

There is a debate among surgeons as to the appropriate time for excision and the most optimal way to surgically reconstruct the corneal defects following removal of such lesions in infants and children [7-10]. The time of surgical excision appears to vary depending on the lesion's original size, growth, and area of involvement, as well as the family's request for removal due to psychosocial issues [8-13]. Numerous surgical techniques have been reported in the literature, from simple excision to lamellar and/or penetrating keratoplasty with corneal-limbal scleral donor graft transplantation, depending upon on the depth, size and site of such lesions [8-11]. Simple excision of corneal dermoids may result in persistent epithelial defect, corneal vascularization 
and scar formation [14]. A number of articles have shown amniotic membrane to have widespread application with or without limbal allografts in ocular and corneal surface reconstruction $[15,16]$. Here we describe a method of superficial lamellar dissection of grade-1 limbal dermoids combined with application of fibrin glue-assisted multilayer amniotic membrane transplantation (AmnioGraft ${ }^{\mathrm{TM}}$, BioTissue Inc, Miami, FL, USA) as a biological substrate for corneal stromal growth, re-epithelization, retardation in postoperative scar formation, and reduction of post-operative pain.

\section{Case}

Institutional review board exemption was granted, parental consent was obtained, and HIPAA regulations were followed. A 6-month old boy had progressive enlargement of an inferotemporal corneal limbal dermoid in his right eye since birth (Fig. 1). Visual acuity testing revealed normal fixation and following pattern for both eyes. No amblyopia was present. Examination for both the alignment and versions were normal. After a period of observation, astigmatic error increased from 1D to 2.25D. Due to progressive enlargement of the mass reported by parents, increasing astigmatic error and the parent's desire to remove the lesion, the decision was made to proceed with surgical excision. The surgical approach was reviewed thoroughly with the parents.

\section{Surgical technique}

The border of the limbal dermoid was marked using a fine marking pen after anterior segment B-scan showed superficial corneal involvement. Preservative-free lidocaine ${ }^{\circledR} 0.75 \%$ with epinephrine for total of $0.1 \mathrm{cc}$ was injected into subconjunctival space inferior to the lesion. A conjunctival peritomy was made at the inferior border of the lesion using blunt Westcott scissors. The surrounding tissue was freed. With the use of a 57 curved crescent blade knife, lamellar dissection of the

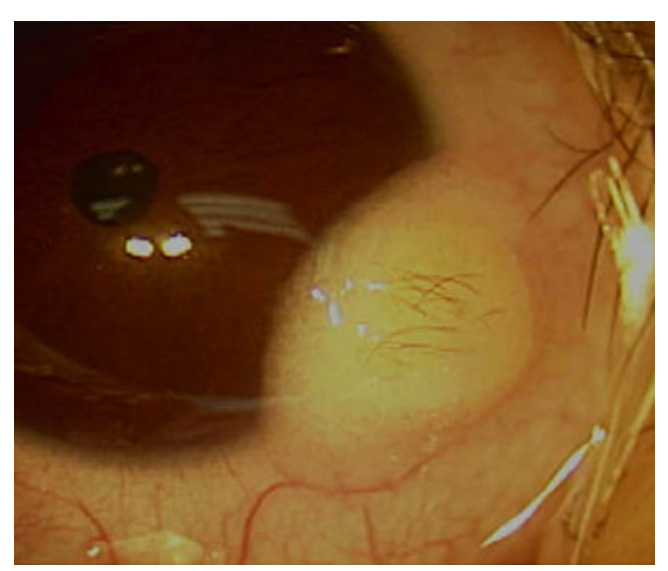

Fig. 1 Preoperative inferotemporal limbal dermoid corneal limbal dermoid was carried out starting from the base of the dome on the sclera moving towards the cornea.

Following complete excision and removal of the dermoid, a longitudinal planar dissection of residual dermoid fibers from the corneal stroma was performed using a 57 straight beaver blade knife. A fine diamond burr was used to smooth out the corneal surface bed. A clear stromal tissue bed became evident following removal of approximately $20 \%$ of corneal stromal tissue measured by an ultrasound pachymeter. Calipers measured the corneal defect to be $3 \times 3 \mathrm{~mm}$.

Fresh amniotic membrane (AmnioGraft ${ }^{\circledR}$, Miami, FL, USA) was folded in a 3-layered sandwich pattern with the orientation of stromal side on the corneal surface and epithelial side up, and then trimmed to the size of the measured corneal defect. The folded amniotic membrane achieved complete filling of the corneal defective depth, and as a result lay at a similar height to the surrounding healthy corneal tissue. Fibrin glue (Tisseel ${ }^{\circledR}$, Baxter Inc, Deerfield, IL, USA) was then applied under the amniotic membrane layers to obtain stability of the membrane and also allow for firm adherence to the corneal defect. An additional amniotic membrane was cut by a trephine to $6 \mathrm{~mm}$ diameter, and was firmly attached using fibrin glue to cover both the bare sclera and over the already placed amniotic membrane extending to the rim of healthy corneal tissue. The recessed conjunctival tissue was repositioned to be adjacent to the amniotic membrane edge and then reattached with fibrin glue. No bare sclera or corneal epithelial defect was present at the conclusion of the procedure.

A subconjunctival injection of preservative-free mixture of marcaine ${ }^{\circledR}$, Ancef ${ }^{\circledR}$ and dexamethasone ${ }^{\circledR} 0.3 \mathrm{cc}$ was administered into the inferior fornix. An additional $0.1 \mathrm{cc}$ of $40 \mathrm{mg} / \mathrm{cc} \mathrm{kenalog}{ }^{\circledR}$ (triamcinolone) was injected into inferior fornix. The patient's eye was pressure-patched after instillation of maxitrol ${ }^{\circledR}$ ointment and a drop of tetracaine (AK-TCaine PF, Sigma Inc, Monticello, IA, USA) for 24 hours.

\section{Results}

At the first post-operative day visit, parents reported regular sleeping and feeding behavior, and no discomfort was noted. Parents did not administer pain medication after discharge and during the first post-operative day. No epithelial defect was evident at this visit. Amniotic membrane was firmly attached (Fig. 2). Our patient continued normal behavior without eye rubbing for the first post-operative week. Direct examination showed presence of amniotic membrane at 4 weeks following surgery (Fig. 3). Corneal transparency continued to improve such that eight weeks postoperatively, amniotic membrane was no longer visible clinically. Conjunctival tissue had completely healed without retraction and minimal corneal opacity was 


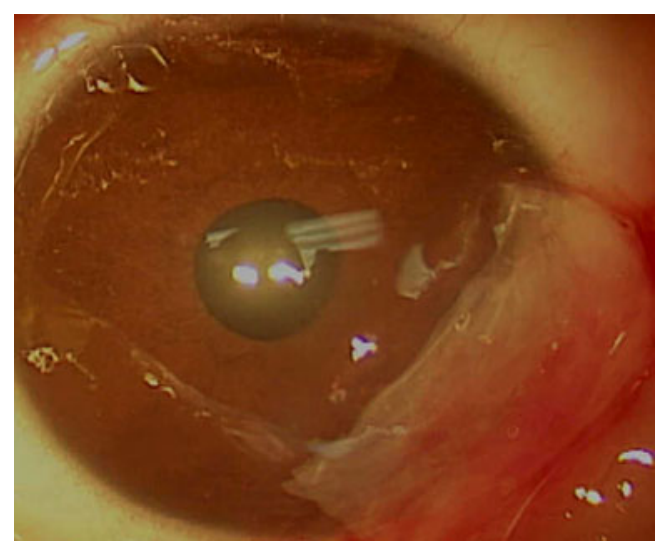

Fig. 2 Post-operative day \#1: amniotic membrane covering the corneal defect

present. Three months post-operatively, the visual acuity was stable. No corneal or conjunctival neovascularization or scar was present (Fig. 4). The astigmatic error remained at 2.25D at 3 months post-operatively.

\section{Discussion}

A number of articles have shown the wide application of amniotic membrane (fresh or preserved) with and/or without limbal allografts for ocular and corneal surface reconstruction [16-21]. Indications of amniotic membrane transplantation for treatment of ocular surface diseases have ranged from cicatricial ocular surface disorders such as Stevens-Johnson syndrome, alkali burn, bullous or band keratopathy, ocular cicatricial pemphigoid to pterygium and conjunctival tumors [21, 22]. Fresh or preserved amniotic membrane has been shown to promote epithelization, reduce inflammation, prevent neovascularization and suppress recurrent subconjunctival fibrosis following symblepharon lysis [21-23] Furthermore, amniotic membrane is known to differentiate into conjunctival epithelial cells [24]. Additionally, recent

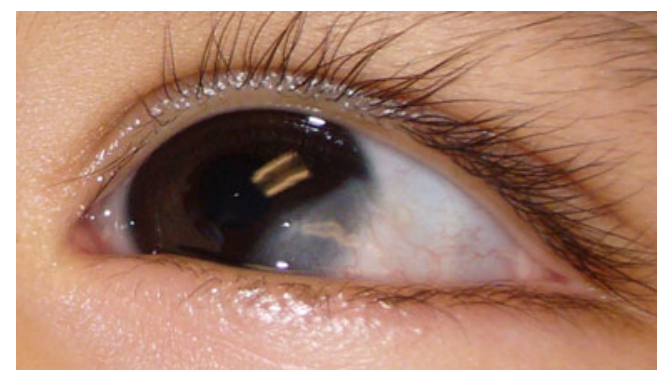

Fig. 3 Post-operative week \#4: corneal defect covered by amniotic membrane. minimal vascularization of $\mathrm{AMG}$ is present

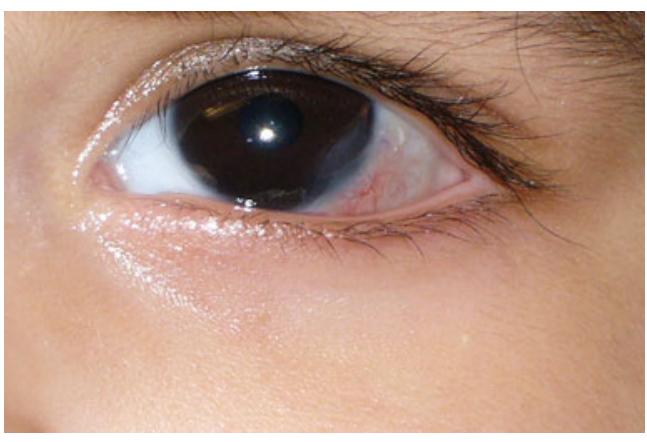

Fig. 4 Post-operative month \#3: corneal defect area remains clear and quiet

advances in the use of fibrin glue in conjunction with amniotic membrane transplantation has significantly enhanced the application of tissues adhesives in ocular surface reconstruction $[25,26]$.

In pediatric eyes with low grade peri-limbal corneal dermoids having predisposition to scar formation following corneal dermoid resection, amniotic membrane transplantation seems to provide an excellent alternative to reduce or prevent post-operative patients' scar fromation. Higher grade ocular surface dermoids should, however, be evaluated for appropriate surgical planning with pre- or peri-operative ultrasound biomcroscopy for their depth of involvement [27, 28]. Simple excision and/or keratectomy of smaller lesions have been shown to lead to pseudo-pterygium and conjunctival symblepharon formation due to surface tear fluid irregularities [14]. In addition, it has been proposed that early surgical intervention facilitates the ease of dissection with less complications, and also results in better final cosmetic and functional results [14]. We believe the amniotic membrane transplantation may also protect limbal stem cell populations from detriment of prolonged inflammation. Furthermore, amniotic membrane tissue provides a natural biological substrate for indigenous corneal stromal growth, remodeling and epithelial cell differentiation [29, 30]. An additional advantage of amniotic membrane transplantation is that it reduces post-operative pain and associated inflammation as it covers the post-operative corneal epithelial defect and corneal nerves as well as the inflammatory cascade. This helps to mitigate post-operative scarring.

Although amniotic membrane has never been cited in the literature to be used following surgical removal of corneal dermoid in pediatric patients, it has been applied in children and in strabismus surgeries to reduce postoperative adhesions [31]. Pre-operative counseling with parents should include potential failure to improve astigmatism. Yamada and colleagues used amniotic membrane in a patient with subconjunctival fibrosis and fat adhesion syndrome with a satisfactory outcome [32]. More significant corneal defects have also been filled and 
reconstructed with multi-layered amniotic membrane [33]. Our rationale for using multilayered amniotic membrane was to achieve volumetric filling of the stromal and epithelial defect to prevent dellen effect. Extensive corneal defects seem to show an improved healing response rate following multilayered amniotic membrane transplantation [34, 35]. In addition, using tissue adhesives in the amniotic membrane transplantation for pediatric corneal dermoid removal permits a sutureless procedure, thereby avoiding future suture exposure and foreign body sensation. Application of fibrin glue also shortens operating times by eliminating suture placement. While application of multilayered amniotic membrane with tissue adhesive in our patient added 7-10 minutes to our procedure, lack of any suture use for the case conserved us more time. This technique also eliminates a return to the operating room for suture removal thereby saving time and significant resources for both the provider and the family. The lack of more than one surgical case as well as a short follow-up period are the main limitations of this report. A larger number of patients as well as a longer follow-up time would be preferable in order to draw final conclusions.

\section{Conclusion}

Although previous surgical techniques of pediatric corneallimbal dermoid removal such as simple excision and/or sclerocorneal graft transplantation have been adequate, they have been shown to result in suture exposure, painful postoperative recovery, and corneal neovascularization, as well as, potentially, additional surgical procedures. Our technique would help eliminate these issues.

Open Access This article is distributed under the terms of the Creative Commons Attribution Noncommercial License which permits any noncommercial use, distribution, and reproduction in any medium, provided the original author(s) and source are credited.

\section{References}

1. Mansour AM, Barber JC, Reinecke RD, Wang FM (1989) Ocular choristomas. Review Surv Ophthalmol 33:339-358

2. Mohan M, Mukherjee G, Panda (1981) Clinical evaluation and surgical intervention of limbal dermoid. Indian $\mathrm{J}$ Ophthalmol 29:69-73

3. Nevares RL, Mulliken JB, Robb RM (1988) Ocular Dermoids. Plast Recontstr Surg 82(959):64

4. Burillon C, Duran L (1997) Solid dermoids of the limbus and the cornea. Ophthalmologica 211:367-372

5. Mann I (1957) Developmental abnormalities of the eye,2nd ed. Lippincott, Philadelphia, pp 357-364
6. Robb RM (1996) Astigmatic refractive errors associated with limbal dermoids. J Pediatr Ophthalmol Strabismus 33:241-243

7. Bourne RA (1961) Epibulbar dermoid tumours of the corneal limbus treated by lamellar keratoplasty. Trans Can Opthalmolog Soc 24:153-158

8. Zaidman GW, Johnson B, Brown SI (1982) Corneal transplantation in an infant with corneal dermoid. Am J Ophthalmol 93:78-83

9. Panton RW, Sugar J (1991) Excision of limbal dermoids. Ophthalmic Surg 22:85

10. Kaufman A, Medow N, Phillips R, Zaidman G (1999) J Treatment of epibulbar limbal dermoids. Pediatr Ophthalmol Strabismus 36:136-140

11. Scott JA, Tan DT (2001) Therapeutic lamellar keratoplasty for limbal dermoids. Ophthalmology 108:1858-1867

12. Shen YD, Chen WL, Wang IJ, Hou YC, Hu FR (2005) Fullthickness central corneal grafts in lamellar keratoscleroplasty to treat limbal dermoids. Ophthalmology 112:1955

13. Watts P, Michaeli-Cohen A, Abdolell M, Rootman D (2002) Outcome of lamellar keratoplasty for limbal dermoids in children. J AAPOS 6:209-215

14. Panda A, Ghose S, Khokhar S, Das HJ (2006) Surgical outcomes of epibulbar dermoids. Pediatr Ophthalmol Strabismus 39:20-25

15. Mader TH, Stulting D (1998) Technique for the removal of limbal dermoids. Cornea 17:66-67

16. Panda A (1999) Amniotic membrane transplantation in ophthalmology (fresh vs. preserved tissue). Br J Ophthalmol 83:1410-1411

17. Tseng SC, Prabhasawat P, Barton K, Gray T, Meller D (1998) Amniotic membrane transplantation with or without limbal allografts for corneal surface reconstruction in patients with limbal stem cell deficiency. Arch Ophthalmol 116:431-441

18. Fernandes M, Sridhar MS, Sangwan VS, Rao GN (2005) Amniotic membrane transplantation for ocular surface reconstruction. Cornea 24:643-653

19. Gomes JA, Romano A, Santos MS, Dua HS (2005) Amniotic membrane use in ophthlalmology. Curr Opin Ophthalmol 16:233-240

20. Tseng SCG, Espana EM, Kawakita T et al (2004) How does amniotic membrane work? Ocular Surface J 2:177-187

21. Yildiz EH, Nurozler AB, Ozkan Aksoy N, Altiparmak UE, Onat M, Karaguzel H (2008) Amniotic membrane transplantation: indications and results. Euro J Ophthalmol 18:685-690

22. Chen Z, Yan J, Yang H, Wu Z, Pang Y, Ai S, Mao Y (2003) Amniotic membrane transplantation for conjunctival tumor. Yan Ke Xue Bao 19:165-167

23. Chuck RS, Graff JM, Bryant MR, Sweet PM (2004) Biomechanical characterization of human amniotic membrane preparations for ocular surface reconstruction. Ophthalmic Res 36:341-348

24. Meller D, Tseng SC (1999) Conjunctival epithelial cell differentiation on amniotic membrane. Invest Ophthalmol Vis Sci 40:878886

25. Kim HK, Park HS (2009) Fibrin glue-assisted augmented amniotic membrane transplantation for the treatment of large noninfectious corneal perforations. Cornea 28:170-176

26. Chan SM, Boisjoly H (2004) Advances in the use of adhesives in ophthalmology. Curr Opin Ophthalmol 15:305-310

27. Grant CA, Azar D (1999) Ultrasound biomicroscopy in the diagnosis and management of limbal dermoid. Am J Ophthalmol 128:365-367

28. Lanzl IM, Augsburger JJ, Hertle RW, Rapuano C, Correa-Melling Z, Santa Cruz C (1998) The role of ultrasound biomicroscopy in surgical planning for limbal dermoids. Cornea 17:604-606

29. Koizumi N, Fullwood NJ, Bairaktaris G, Inatomi T, Kinoshita S, Quantock AJ (2000) Cultivation of corneal epithelial cells on intact and denuded human amniotic membrane. Invest Ophthalmol Vis Sci 41:2506-2513 
30. Connon CJ, Nakamura T, Quantock AJ, Kinoshita S (2006) The persistence of transplanted amniotic membrane in corneal stroma. Am J Ophthalmol 141:190-192

31. Shea H, Gasa V, Hayashida Y (2009) The use of amniotic membrane in reducing adhesions after strabismus surgery. $\mathrm{J}$ AAPOS 13:99-101

32. Yamada M, Shinoda K, Hatakeyama A, Nishina S, Mashima Y (2001) Fat adherence syndrome after retinal surgery treated with amniotic membrane transplantation. Am J Opthalmol 132:280-282
33. Rodríguez-Ares MT, Touriño R, López-Valladares MJ, Gude F (2004) Multilayer amniotic membrane transplantation in the treatment of corneal perforations. Cornea 23:577-583

34. Hanada K, Shimasaki J, Shimmura S, Tsubota K (2001) Multilayered amniotic membrane transplantation for severe ulceration of the cornea and sclera. Am J Ophthalmol 131:324-331

35. Ozcan AA (2008) Autologous human fibrin glue in multilayered amniotic membrane transplantation. Ann Ophthalmol 40:107-109 